\title{
Estudo comparativo da adoção de práticas de tecnologia da informação verde em instituições de ensino superior
}

A Tecnologia da Informação (TI) Verde emergiu como uma alternativa voltada para a redução do impacto dos recursos tecnológicos no meio ambiente. Seu conjunto de práticas envolve desde a observância de selos de qualidade na aquisição de equipamentos, a gestão do uso consciente destes recursos, culminando com o descarte dos resíduos eletroeletrônicos (REEs). No Brasil, a Política Nacional de Resíduos Sólidos (PNRS) consiste em um instrumento legal para assegurar a destinação ambientalmente adequada dos resíduos sólidos, incluindo os REEs, que pode também ser aplicada às instituições de ensino superior de todo o país, uma vez que se encontram submetidas ao contexto regulatório brasileiro. Esta pesquisa realizou um estudo comparativo sobre a adoção de práticas de TI Verde entre instituições de ensino superior públicas e privadas à luz da teoria institucional, advinda das Ciências Administrativas, das normas, leis e regulamentos ambientais, para verificar as dificuldades de implantação e compreender como as pressões institucionais e a legislação ambiental influenciam neste processo. A partir de um levantamento tipo survey online foram coletados dados por meio de questionários aplicados com gestores de TI e de administração de 06 (seis) instituições de ensino superior públicas e privadas, localizadas no estado de Alagoas, na região nordeste do Brasil. Os resultados sinalizaram para um panorama de desconhecimento das práticas de TI Verde por parte das instituições, bem como das legislações e regulamentos ambientais, especialmente por parte das IES públicas, o que levou à proposição de uma cartilha de recomendações contendo 23 problemas identificados e, a partir da observação das normas e regulamentações, foram apresentadas as respectivas sugestões, com a perspectiva de serem encaminhadas aos gestores das IES para adoção de práticas de TI Verde.

Palavras-chave: Sustentabilidade; Tecnologia da Informação Verde; Instituições de Ensino Superior; Teoria Institucional.

\section{A comparative study on the adoption of green information technology practices in higher education institutions}

Green Information Technology (IT) has emerged as an alternative aimed at reducing the impact of technological resources on the environment. Its set of practices involves: observation of quality seals in the equipment acquisition, management of the conscious use of resources, culminating in the disposal of electronic waste (e-waste). In Brazil, a National Solid Waste Policy consists of a legal instrument to ensure the environmentally appropriate disposal of waste, which can also be used by higher education institutions, since they were submitted to the Brazilian regulatory context. This research undertook a comparative study on the adoption of Green IT practices between public and private higher education institutions in the light of institutional theory derived from Administrative Sciences, environmental standards, laws and regulations, to verify the implementation difficulties and understand how institutional pressures and environmental legislation influence this process. An online survey was adopted. Data were collected through questionnaires applied with IT and administration managers from six public and private higher education institutions, located in Alagoas State, Brazil. The results signaled a panorama of unfamiliarity with Green IT practices by institutions, as well as environmental laws and regulations, especially by public institutions, which led to the proposition of a recommendations guide containing 23 identified problems and your possible solutions, based on the rules and regulations, in the perspective of being referred to the managers for the adoption of sustainable practices.

Keywords: Sustainability; Green Information Technology; Higher Education Institutions; Institutional Theory.

Topic: Logística Reversa

Reviewed anonymously in the process of blind peer.
Received: 05/05/2020

Approved: 01/06/2020
Ismar Macário Pinto Junior (iD)

Universidade Tiradentes, Brasil

http://lattes.cnpq.br/1182940612184517

http://orcid.org/0000-0001-8244-2459

ismarmacario@gmail.com

Mônica Ximenes Carneiro da Cunha (iD

Instituto Federal de Alagoas, Brasil

http://lattes.cnpq.br/1775024859845111

http://orcid.org/0000-0002-5869-9358

mxcc@hotmail.com

Marcílio Ferreira de Souza Júnior ib

Universidade Federal Rural de Pernambuco, Brasil

http://lattes.cnpq.br/2702843581642246

http://orcid.org/0000-0003-0237-392x

marcilio.souzair@ufrpe.br
Referencing this:

PINTO JUNIOR, I. M.; CUNHA, M. X. C.; SOUZA JÚNIOR, M. F.. Estudo comparativo da adoção de práticas de tecnologia da informação verde em instituições de ensino superior. Revista lbero-Americana de Ciências Ambientais, v.11, n.4, p.270-286, 2020. DOI: http://doi.org/10.6008/CBPC2179-6858.2020.004.0023 


\section{INTRODUÇÃO}

A evolução tecnológica vem provocando grandes alterações no meio ambiente e um dos fatores agravantes tem sido a obsolescência programada, que reflete no aumento do consumo de recursos naturais não renováveis e, por sua vez, na geração acelerada de resíduos de equipamentos eletroeletrônicos (REEs), que contêm em sua composição substâncias tóxicas e perigosas, como mercúrio, fósforo e chumbo, com alto potencial de geração de danos à saúde humana e ao meio ambiente, quando destinados de forma inadequada (RODRIGUES et al., 2015).

O desenvolvimento de novas tecnologias e o aumento do consumo de bens duráveis acarretou na concepção de leis e normativos que objetivam assegurar a destinação ambientalmente adequada dos resíduos sólidos, tal como preceitua a Lei no 12.305/2010, que instituiu no Brasil a Política Nacional de Resíduos Sólidos (PNRS) (BRASIL, 2010). Um dos instrumentos da PNRS se refere ao ciclo de vida dos produtos e envolve a coleta seletiva e os sistemas de logística reversa.

A PNRS trata a logística reversa como um conjunto de ações e procedimentos para nortear o mecanismo da coleta e do retorno dos resíduos sólidos ao setor empresarial, para o devido reaproveitamento ou para outro destino ambientalmente adequado. Também busca lidar com a responsabilidade compartilhada do ciclo de vida dos produtos a partir de acordos setoriais, compreendido como "um conjunto de atribuições individualizadas e encadeadas dos fabricantes, importadores, distribuidores e comerciantes, dos consumidores e dos titulares dos serviços públicos de limpeza urbana e de manejo dos resíduos sólidos, para minimizar o volume de resíduos sólidos e rejeitos gerados" (BRASIL, 2010). Um dos setores previstos no acordo é o das indústrias de eletroeletrônicos, que sinaliza para a responsabilização destas empresas pelos resíduos que geram até o fim de seu ciclo de vida e que as mesmas devem se preocupar em prover meios para recolher esses resíduos e destiná-los adequadamente.

Após dez anos da PNRS, com a publicação do Decreto no 10.240, de 12 de fevereiro de 2020, o Brasil começou a contar também com regras mais claras para a implementação de um sistema de logística reversa de produtos eletroeletrônicos e seus componentes de uso doméstico (BRASIL, 2020). O referido decreto sinalizou um prazo de cinco anos para implantação de cinco mil pontos de coleta e destinação dos resíduos eletroeletrônicos. Demonstrando, assim, uma preocupação com os impactos ambientais do consumo acelerado dos produtos eletrônicos, que já são produzidos com obsolescência programada.

Devido aos impactos que os produtos oriundos do setor de tecnologia da informação (TI) vêm causando ao meio ambiente (DEMAJOROVIC et al., 2016), emergiu na literatura um conjunto de práticas que visa conciliar o uso e descarte dos equipamentos de TI com as políticas de sustentabilidade dentro do ambiente organizacional, promovendo benefícios para o meio ambiente e para as instituições, denominado TI Verde ou Green IT (SACHUCK et al., 2008; LUNARDI et al., 2014).

Murugesan (2008) ressaltou que a TI Verde se ancora em práticas para projetar, fabricar, utilizar e descartar produtos e subprodutos de informática, pressupondo efetividade para garantir níveis mínimos de impactos negativos ao meio ambiente. É importante ressaltar que a TI Verde também abrange o conjunto de 
iniciativas e programas que direta ou indiretamente estão relacionados com a sustentabilidade ambiental nas organizações por tratar de eficiência energética no uso de hardware e software e descarte de equipamentos obsoletos (JENKIN et al., 2010).

As principais práticas da TI Verde foram agrupadas por Lunardi et al. (2014) em ações, dentre elas: aquisição de equipamentos com selo verde de eficiência energética e sem componentes tóxicos; monitoramento e controle de energia; busca e atualização de boas práticas; e consciência socioambiental, voltada a ações como reciclagem, descarte, campanhas e parcerias. Cabe salientar que uma das práticas da TI Verde é justamente a destinação dos resíduos eletroeletrônicos, ou seja, implantar a TI Verde também é atender o que dispõe a legislação vigente no país.

Por outro lado, Diniz (2016) alertou que as instituições públicas de ensino necessitam aprimorar o processo de descarte dos seus resíduos eletrônicos, em especial os equipamentos de informática. Algumas instituições de ensino superior (IES) têm iniciado o desenvolvimento de seus próprios projetos pilotos para o desfazimento correto de seus equipamentos de informática, descortinando um cenário relevante para a proposta desta pesquisa, pois o arcabouço da PNRS aliado à TI Verde também pode ser aplicado às IES de todo o país que, por sua vez, encontram-se submetidas ao contexto regulatório brasileiro.

De fato, ao investigarem os procedimentos de descarte de equipamentos eletrônicos em uma universidade brasileira, Watanabe et al. (2019) identificaram que não havia na instituição um plano de gestão de REEs, que acabavam sendo armazenados inapropriadamente, impossibilitando seu reaproveitamento. Por sua vez, Minotto et al. (2015) já haviam chegado à mesma conclusão em um estudo similar envolvendo outra universidade, que também não contava com um plano de gerenciamento de resíduos sólidos, o que acarretava em um baixo grau de aproveitamento dos resíduos gerados. Ressalta-se que essas pesquisas se limitaram a um estudo de caso único. Adotando um desenho metodológico mais amplo, envolvendo três universidades públicas, Sadalla (2019) analisou os procedimentos de desfazimento de IES paulistas e concluiu que essas instituições destinaram seus equipamentos de informática patrimoniados de acordo com a lei, por meio de doação ou venda para estabelecimentos devidamente certificados.

Vale destacar que os problemas com descarte de equipamentos de informática e demais práticas estabelecidas pela TI Verde podem se apresentar de maneiras distintas nas IES públicas e privadas, dada as diferenças legais destas, enfrentando mais dificuldade ou facilidade na execução de determinada prática. Um dos exemplos é a Lei Federal 8.666/93, que instituiu normas para licitações e contratos da Administração Pública, mas não se aplica às IES privadas. Em muitos casos, a supracitada lei de licitações torna o processo de compras complexo e muito lento, o que dificulta a renovação dos recursos tecnológicos e, inclusive, até o descarte dos que estão obsoletos.

Face essa problemática, a presente pesquisa realizou um estudo comparativo entre 06 (seis) instituições de ensino superior públicas e privadas, localizadas no estado de Alagoas, na região Nordeste do Brasil, à luz das normas, leis e regulamentos ambientais. Devido ao caráter regulador que as IES estão submetidas, a presente pesquisa incorporou a teoria institucional, assim como foi delineado em Chen et al. (2011), como lente teórica para analisar as dificuldades de implantação e compreender como as pressões 
institucionais e a legislação ambiental influenciam na implementação das práticas de tecnologia da informação verde no âmbito dessas organizações. Após o levantamento dos problemas, foi proposta uma cartilha de recomendações composta por soluções para nortear a implantação destas práticas nas IES.

O artigo foi organizado da seguinte forma: a seção 2 apresenta as práticas de TI Verde, os aspectos resgatados da teoria institucional e as principais regulamentações ambientais. Na seção 3 são detalhados os procedimentos metodológicos. Já na seção 4 são apresentados os resultados da pesquisa lastreados em um levantamento do tipo survey online junto às instituições públicas e privadas. Por fim, na seção 5, são apresentadas as conclusões gerais e os trabalhos futuros.

\section{REVISÃO TEÓRICA}

Esta seção aborda as práticas de tecnologia da informação verde, os aspectos da teoria institucional e as principais normas e regulamentações ambientais, que foram relevantes para a presente pesquisa.

\section{Tecnologia da Informação Verde e suas práticas}

A tecnologia da informação verde ou TI Verde é um conjunto de práticas que visa à redução dos impactos dos equipamentos eletroeletrônicos em todas as fases do ciclo de vida destes, ou seja, desde a sua concepção até a destinação final ambientalmente adequada (BOSE et al., 2012), adotando práticas ecoeficientes desde a fabricação dos equipamentos, passando pela aquisição dos produtos e serviços com uma gestão responsável em toda a cadeia envolvida. TI Verde consiste em um termo genérico relacionado às medidas e atividades do departamento de TI das empresas e visam contribuir para os objetivos orientados pela sustentabilidade e pela responsabilidade social corporativa (KIM et al., 2010; CHEN et al., 2011).

Portanto, trata-se de um movimento técnico e social que visa implementar políticas, práticas, estratégias e produtos de software e hardware com o intuito de melhorar e promover a sustentabilidade ambiental, deixando o uso da tecnologia computacional menos prejudicial ao meio (SALLES et al., 2016). E que tem por finalidade reduzir os impactos gerados pela tecnologia da informação, trabalhando a conscientização agregada à conservação ambiental e orientando as empresas nas boas práticas de gestão.

Segundo Lunardi et al. (2014), a TI Verde ainda é um movimento recente e, por conta disto, não apresenta um conceito inteiramente definido, corroborando com Chen et al. (2011), nem tão pouco apresenta um conjunto de práticas aceitas e aplicadas por todas as organizações. No entanto, estes autores afirmaram que a adoção de suas práticas pode gerar valor para as organizações e para a sociedade, economizando gastos com energia, papel, água, transporte, espaço físico, manutenção e descarte e melhorando a imagem da empresa como uma instituição que valoriza seus funcionários e respeita o meio ambiente.

As principais práticas da TI Verde foram agrupadas por Lunardi et al. (2014) em quatro fatores: ações, que envolvem desde a remoção dos equipamentos que não estão em uso, aquisição de equipamentos com selo verde de eficiência energética e sem componentes tóxicos, até o descarte adequado dos mesmos; monitoramento, que envolve o controle dos custos de manutenção dos equipamentos, controle de energia, 
gerenciamento de desempenho; busca e atualização de boas práticas, que envolve o conhecimento sobre como as diferentes tecnologias computacionais podem funcionar de forma mais eficiente, tendências de tecnologias mais limpas, economia obtida por práticas adotadas por outras empresas; e consciência socioambiental, voltada a ações como reciclagem, descarte, campanhas e parcerias.

A TI Verde adota o termo lixo eletrônico (e-lixo) como elemento mais contundente de impacto ambiental direto, que são os resíduos eletroeletrônicos, por consistirem nos equipamentos que após seu ciclo de vida devem ser descartados de forma adequada como prevê a legislação. Quando isto não acontece o resultado é bastante negativo para o meio ambiente, uma vez que estes possuem em sua composição diversos elementos químicos que são extremamente nocivos, tais como: chumbo, cromo, mercúrio, arsênio, cádmio, entre outros (MAITINO NETO et al., 2012). Além disso, os resíduos eletroeletrônicos são compostos por materiais, como plásticos, vidros e metais, que podem ser recuperados e retornados como insumo para a indústria de transformação.

Desta forma, o uso ineficiente da TI, além de prejudicar o meio ambiente, pode resultar em maiores custos para as organizações (MELVILLE, 2010). Desenvolver um ambiente organizacional sustentável em harmonia com os anseios da sociedade atual impõe às organizações a adoção e execução de políticas visando a busca por produtos e práticas que minimizem os efeitos danosos ao meio ambiente, provocados pelo uso intensivo da tecnologia da informação. Ainda que a TI venha representando uma parte significativa dos problemas ambientais, a abordagem chamada de TI verde não considera mais a tecnologia como uma razão para os problemas ambientais, mas sim como uma potencial solução (SALLES et al., 2016).

\section{Teoria Institucional}

As organizações começaram a ser vistas para além de meros sistemas de produção, mas sim como sistemas sociais e culturais que, ao longo do tempo, estão sujeitas às pressões do ambiente social (SCOTT, 2001). Tal fenômeno foi designado nas Ciências Administrativas, por Selznick (1996), como um processo de institucionalização e está ligado a uma necessidade de sobrevivência, de reconhecimento e de adaptação da organização aos interesses que existem em seu ambiente.

Além do conceito essencial de institucionalização, a teoria institucional enfatizou a influência do ambiente sobre a organização e apresentou o isomorfismo como fator vital para a sua sobrevivência. 0 isomorfismo, sob esta ótica, explica a adoção de práticas organizacionais semelhantes pelas instituições. De acordo com Dimaggio et al. (2007), as organizações são orientadas por objetivos e pela busca da eficiência, legitimadas em um determinado contexto social, que se materializa na homogeneidade das práticas organizacionais. Ou seja, se uma instituição tem uma prática habitualmente reconhecida como adequada pela sociedade, as outras tendem a executar a mesma ação, mesmo sem dispor de um estudo claro do quanto seria benéfica para ela.

Dimaggio et al. (2007) ressaltaram três mecanismos que provocam mudanças isomórficas institucionais: 1) isomorfismo coercitivo, que resulta tanto de pressões formais quanto informais exercidas sobre as organizações, que podem ser sentidas como coerção, como persuasão, ou simplesmente como um 
convite a adoção ou à obediências de ordens governamentais; 2) isomorfismo mimético, que ocorre quando o ambiente de incerteza impulsiona à imitação de práticas adotadas por outras organizações; e 3) isomorfismo normativo, associado à profissionalização, que por sua vez está relacionado à educação formal, a partir da adoção de práticas delineadas por especialistas ou oriunda do crescimento e da constituição de redes profissionais que perpassam as organizações, como por exemplo as IES, e por meio das quais novos modelos são rapidamente difundidos.

\section{Normas e regulamentos sobre resíduos eletroeletrônicos}

O contexto das IES envolve o compartilhamento de um conjunto de normas e rotinas de trabalho, cujo pilar está associado ao isomorfismo normativo tratado por Dimaggio et al. (2007), conforme explicado na subseção anterior. Os governos se baseiam em normas ao elaborar a legislação ou documentos com diretivas para os setores cujas atividades provocam impacto ambiental. As normas são usadas para estabelecer os detalhes técnicos, permitindo que a legislação se concentre em objetivos políticos de longo prazo (GIANELLI, 2016) como, por exemplo, a proteção da saúde pública e da qualidade ambiental e o incentivo à indústria da reciclagem, no âmbito da PNRS. Frisa-se que tais características corroboram com a aplicabilidade do pilar normativo da teoria institucional no contexto da presente pesquisa.

Muitas dessas normas regulamentadoras são criadas com base em organismos internacionais e caracterizam-se por um conjunto de padrões de processos em sua cadeia produtiva, com foco na qualidade do produto final de forma a não ser prejudicial ao meio ambiente (GIANELLI, 2016), sendo, por isso, adotadas por empresas privadas. Isso Ihes confere as certificações, que garantem maior destaque, visibilidade e vantagem competitiva.

Dentre as normas com enfoque sustentável destaca-se a ISO 14001, que é uma ferramenta que auxilia as empresas a controlar os aspectos ambientais presentes em suas atividades e minimizar os impactos decorrentes das interações do aspecto com o meio. Esta norma fornece elementos para implantar um sistema de gestão ambiental, fazendo com que a organização planeje, organize e execute suas atividades de forma ambientalmente correta (MAITINO NETO et al., 2014).

Outros dois instrumentos importantes, neste contexto ambiental, são: a Política Nacional de Meio Ambiente (PNMA), que criou o dispositivo da fiscalização e controle no âmbito ambiental, e a Política Nacional de Resíduos Sólidos (PNRS), que estabeleceu que as empresas são responsáveis pelos produtos que manuseiam em todo o seu ciclo de vida, ou seja, desde o início do processo até o final do ciclo quando restam apenas os resíduos gerados e, pelo descumprimento, cabem inclusive sérias penalidades (PNRS, 2010).

Recentemente foi publicado um decreto de $\mathrm{n}$ 0 10.240/2020 que regulamentou a questão da logística reversa de produtos eletroeletrônicos e seus componentes de uso doméstico, disposta na PNRS. O texto deixa claro as responsabilidades dos fabricantes e importadores relacionadas ao descarte adequado destes resíduos de forma a reduzir os impactos ambientais e prevê que as empresas podem se associar para criação de entidades que vão realizar o trabalho operacional e de gestão do sistema de logística reversa.

Pode-se dizer que a Norma ISO 14001, juntamente com as três legislações supracitadas, compõem o 
conjunto de regramentos que mais interfere ou pode interferir no aspecto sustentável de uma organização, tal como as IES estudadas no campo desta pesquisa, cujo delineamento metodológico será descrito a seguir.

\section{METODOLOGIA}

O enfoque metodológico da pesquisa foi quantitativo, pois buscou identificar e mensurar variáveis a partir da coleta de dados realizada por uma pesquisa de levantamento do tipo survey online (LEEUW et al., 2008), que permitiu a consecução de um estudo comparativo entre instituições públicas e privadas, localizadas no estado de Alagoas, na região nordeste do Brasil. De acordo com Gil (2008), o método comparativo consiste na investigação de indivíduos, classes, fenômenos ou fatos, com vistas a ressaltar as diferenças e similaridades entre eles.

Desta forma, o objeto de estudo foram instituições de ensino superior (IES) públicas e privadas alagoanas de maior relevância. O grau de relevância adotado foi o número de alunos e a amplitude de atuação das instituições dentro do estado, considerando as que possuem vários campi. Adotando este critério foram selecionadas 02 (duas) instituições públicas federais e 04 (quatro) instituições privadas.

Ressalta-se que as IES participantes da pesquisa são regidas por leis federais e vinculadas ao Ministério da Educação. Mesmo instituições que pertencem a estados ou municípios estão sob essa regência, uma vez que as próprias leis estaduais de educação são alinhadas com a lei federal e não podem ir de encontro a estas. E o mesmo ocorre com as instituições particulares, que também são regidas e fiscalizadas pelo referido ministério, sendo visitadas periodicamente quanto ao cumprimento das leis e diretrizes da educação superior. Somadas, as seis IES ofertam 244 cursos de graduação e de pós-graduação, atendendo cerca de 67 mil alunos e dispondo de quase 4 mil servidores entre docentes e técnicos administrativos.

Os respondentes selecionados para a pesquisa foram os gestores de tecnologia da informação e os gestores administrativos das IES. Estes poderiam ser técnicos, coordenadores, gerentes, diretores ou outra função de gestão similar às citadas. Com relação aos gestores de $\mathrm{Tl}$, a escolha se justifica pelo fato de que estes profissionais possuem conhecimento específico na área e o cargo ocupado exigir que estes estejam permanentemente cientes da situação da sua área na organização. No caso dos gestores administrativos a percepção destes é importante porque na maior parte dos casos são quem definem aquisições, procedimentos de uso e descarte de equipamentos.

O instrumento de coleta de dados foi elaborado com base em um questionário estruturado, que agrupou 37 (trinta e sete) as questões em seis blocos de perguntas, delimitando as dimensões a serem estudadas: (1) conhecimento sobre TI verde e programas de sustentabilidade, (2) Práticas de TI verde executadas pela instituição, (3) Cópia de práticas de outras instituições, (4) Formas de aquisição, uso e descarte, (5) conhecimento sobre os normativos e legislação, (6) perfil do respondente.

Foram realizadas visitas às instituições para explicação da pesquisa e execução do procedimento de coleta, sendo que o instrumento foi disponibilizado de forma online usando o Google Forms. O link para o questionário foi enviado por e-mail e por aplicativo de mensagens aos respondentes selecionados. A percepção dos respondentes foi avaliada mediante uma adaptação da escala de Likert de 5 (cinco) pontos. 
No total, foram obtidos 18 (dezoito) questionários respondidos, sendo 10 (dez) de IES públicas e 08 (oito) de privadas. Tal amostra foi considerada adequada porque representou os principais campi das instituições selecionadas e respectivos gestores que formaram o público-alvo. A análise das respostas do questionário foi feita mediante tratamento estatístico descritivo, a partir de gráficos gerados pela ferramenta online Google Forms, e segundo os pressupostos da análise de conteúdo (BARDIN, 2011) no que se refere aos comentários dos campos abertos, com o objetivo de analisar se a instituição pesquisa, desenvolve, executa, fiscaliza o cumprimento das práticas de TI VERDE apontadas e em qual nível.

Após o levantamento e a análise descritiva dos dados, foi empreendida uma averiguação de quais aspectos abordados no questionário, referentes às práticas de TI Verde nas IES, seriam importantes agrupar no formato de uma cartilha de recomendações, que consistiu em um produto técnico resultante da pesquisa, elencando quais as maiores dificuldades encontradas e oferecendo sugestões aos gestores acerca de como estas poderiam ser tratadas frente à legislação ambiental vigente.

\section{RESULTADOS E DISCUSSÃO}

Os resultados desta pesquisa consistiram na identificação e comparação das práticas de TI Verde entre as instituições de ensino participantes, que revelaram as diferenças em termos de conhecimento e de ações sobre as referidas práticas. Por sua vez, as análises embasaram a confeç̧ão de uma cartilha de recomendações para adoção de práticas de TI Verde para IES, que foi diagramada e algumas páginas serão exibidas ao longo desta seção.

\section{Análise comparativa das respostas das IES sobre suas práticas de TI Verde}

Conforme informado anteriormente, o instrumento de coleta de dados foi elaborado com 37 questões, no entanto, devido à limitação de espaço, para fins deste artigo, foram exibidos os resultados encontrados a partir de 15 questões consideradas mais relevantes. Inicialmente, foi avaliado o grau de conhecimento das instituições sobre programas ou sistemas de gestão sustentável, revelando que conheciam apenas dois programas: eficiência energética e redução de desperdício, sendo citados por cerca de $70 \%$ delas. A ISO 14001 e o programa de produção mais limpa foram citados em apenas $11 \%$ dos casos. A eficiência energética é mais conhecida pelas IES públicas, sendo citado por $80 \%$ destas, e por $60 \%$ no caso das privadas. O programa de redução de desperdício é citado por todas as instituições privadas e por apenas metade das públicas.

Sobre as práticas de TI Verde mais utilizadas nas IES, as mais comumente adotadas nas instituições estavam associadas à impressão frente e verso e ao compartilhamento de impressão, sem diferenças significativas entre públicas e privadas (gráfico 1). Outra prática muito citada, por mais de $70 \%$ das instituições em geral, foi a videoconferência. Computação na nuvem (cloud Computing) apresentou uma diferença significativa entre as IES, sendo citada por apenas $20 \%$ das públicas e por quase $90 \%$ das privadas. 


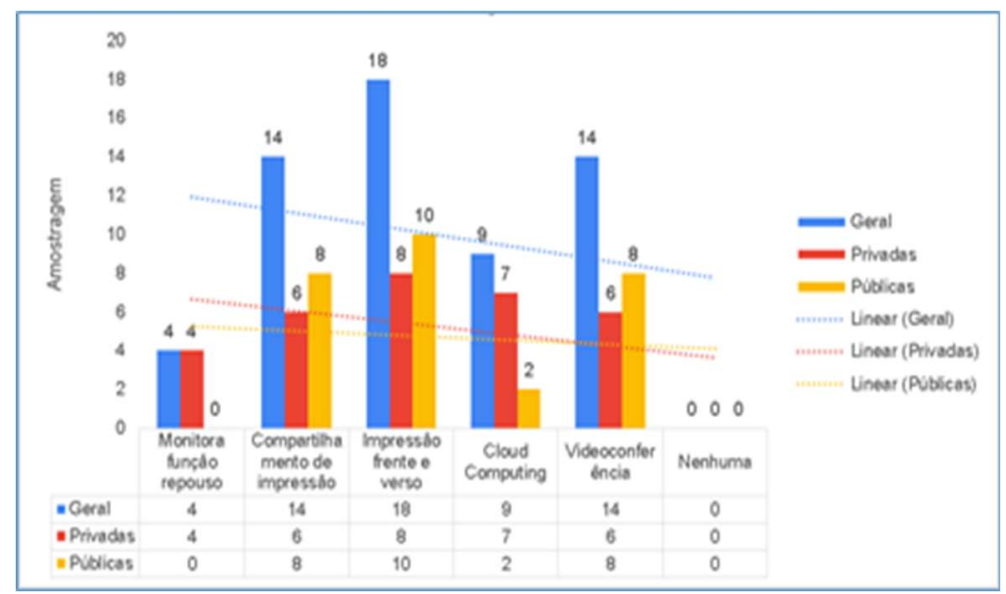

Gráfico 1: Práticas de TI Verde adotadas nas instituições de ensino.

Os resultados apresentados no gráfico 2 demonstram uma polarização nas respostas referentes à aquisição de equipamentos com selo verde. No que concerne às instituições privadas, 50\% sempre ou quase sempre procuram comprar equipamentos com selos verdes. Nas IES públicas, por sua vez, a realidade se mostra diferente, provavelmente devido ao custo mais elevado destes produtos, às vezes incompatíveis com o orçamento disponível.

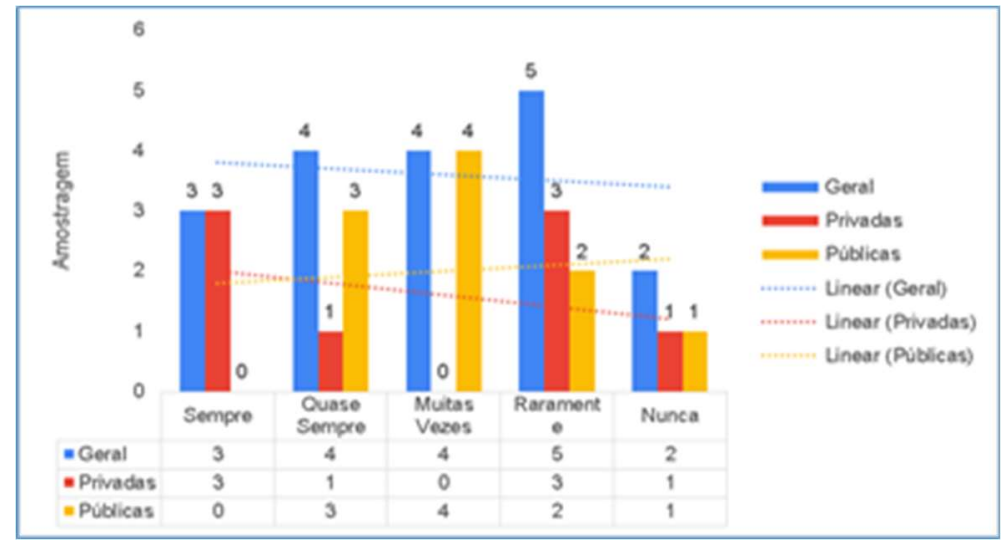

Gráfico 2: Aquisição de equipamentos computacionais com selo verde de qualidade.

O gráfico 3 ilustra os resultados referentes à adoção de medidas para gerenciar eletronicamente os documentos (GED) da instituição, demonstrando que $94 \%$ das instituições adotam esta prática, sendo um percentual maior no caso das privadas, onde $90 \%$ adotam muitas vezes ou quase sempre. No caso das públicas, apenas $50 \%$ adotam sempre ou quase sempre.

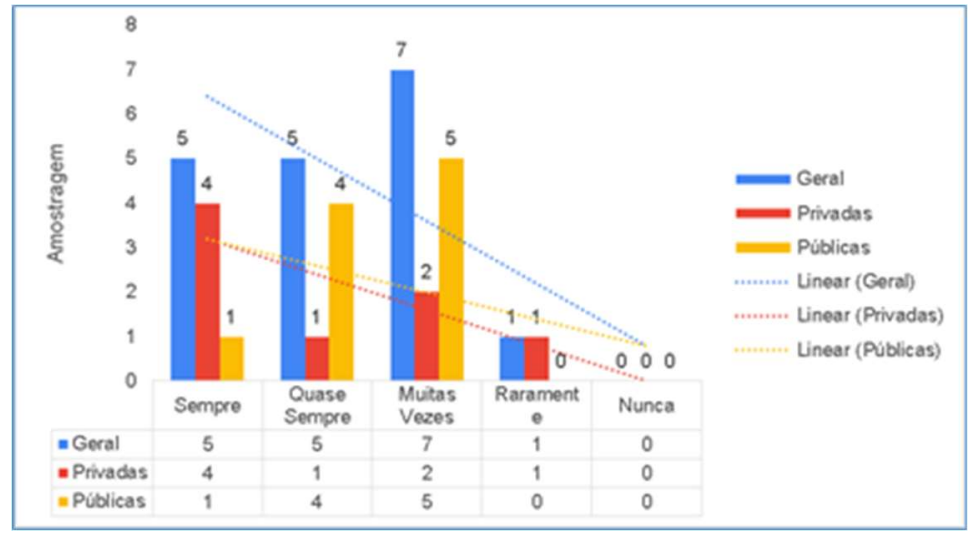

Gráfico 3: Adoção de medidas para gerenciar eletronicamente os documentos. 
O gráfico 4a apresenta um panorama acerca de como as instituições pesquisadas resolveram adotar as práticas que já são executadas, se por força de leis ou normativos internos, se por influência de outras instituições coirmãs ou concorrentes, conforme preconiza a teoria institucional que foi adotada como lente teórica para o estudo.

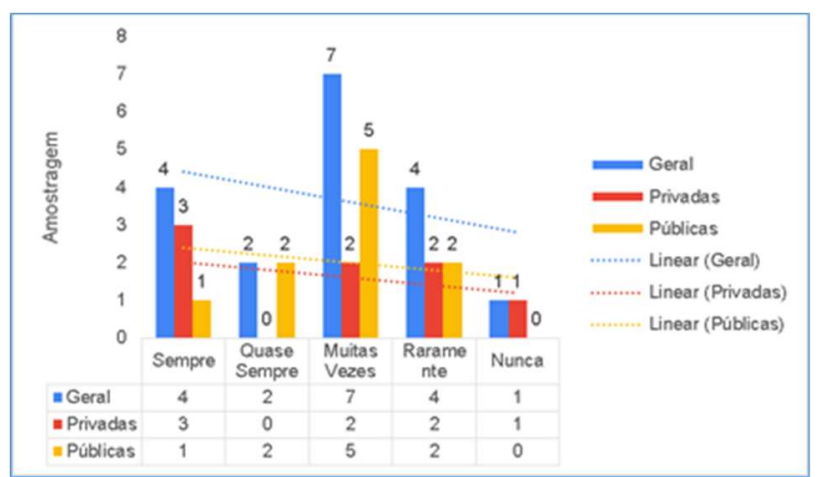

Gráfico 4a: Adoção de práticas de TI verde por imposição de normativos governamentais.

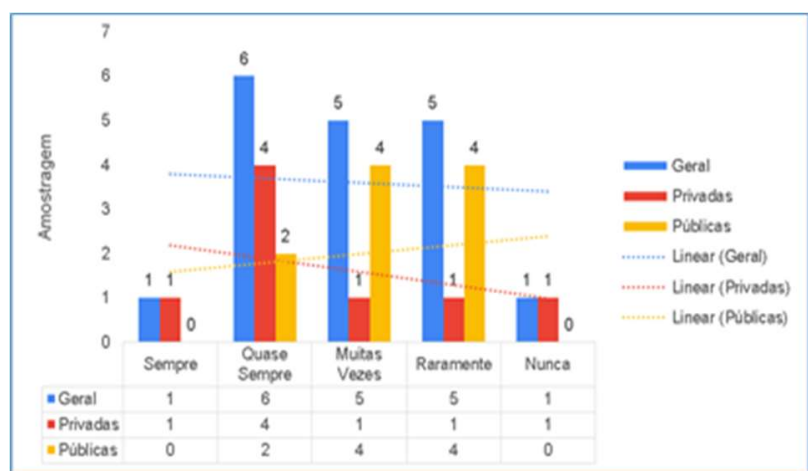

Gráfico 4b: A instituição cópia práticas de TI Verde bemsucedidas de outras instituições coirmãs.

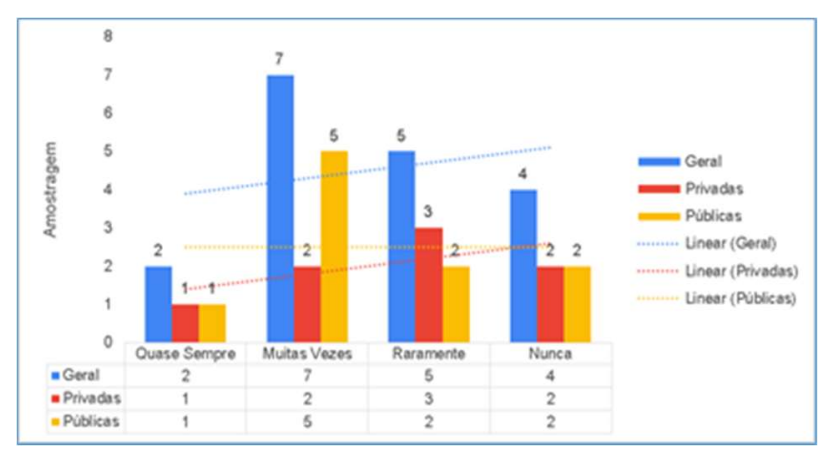

Gráfico 4c: Cópia de práticas de TI Verde bem-sucedidas de outras instituições concorrentes.

Por sua vez, no gráfico $4 \mathrm{~b}$, observa-se que mais de $70 \%$ das instituições afirmaram executar as práticas por força de atos normativos com certa frequência. Este resultado sinaliza para o fato de que as instituições sofrem pressão normativa para atender alguma obrigatoriedade legal. $O$ gráfico $4 \mathrm{c}$ exibe os resultados sobre a cópia de práticas bem-sucedidas em instituições coirmãs, indicando que $66,6 \%$ das instituições copiam práticas com certa frequência. Esta tendência positiva foi influenciada pelas instituições privadas, pois em $62,5 \%$ dos casos estas IES copiam as práticas das coirmãs.

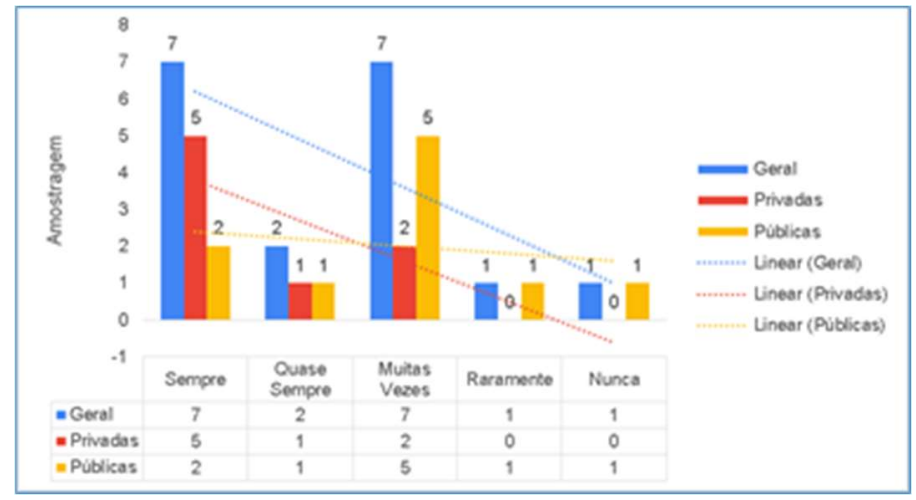

Gráfico 5: As práticas de TI Verde adotadas por outras IES influenciam nas atitudes do gestor.

O gráfico 5 revela se as práticas de TI verde adotadas em outras IES exercem influência nas atitudes 
do gestor. O resultado mostra que $50 \%$ dos respondentes admitiram que suas decisões são sempre ou quase sempre influenciadas pelas práticas executadas em outras instituições. Isso corrobora com o fato de que se as instituições desenvolverem métodos de mapeamento de processos que deram certo de outras, sejam estas públicas ou privadas, estes resultados tendem a influenciar a decisão do gestor. 0 gráfico 6 descreve com que frequência ocorre a remoção dos equipamentos eletroeletrônicos que não estão mais em uso nas instituições. $66 \%$ das IES responderam que frequentemente removem os equipamentos computacionais que não estão em uso.

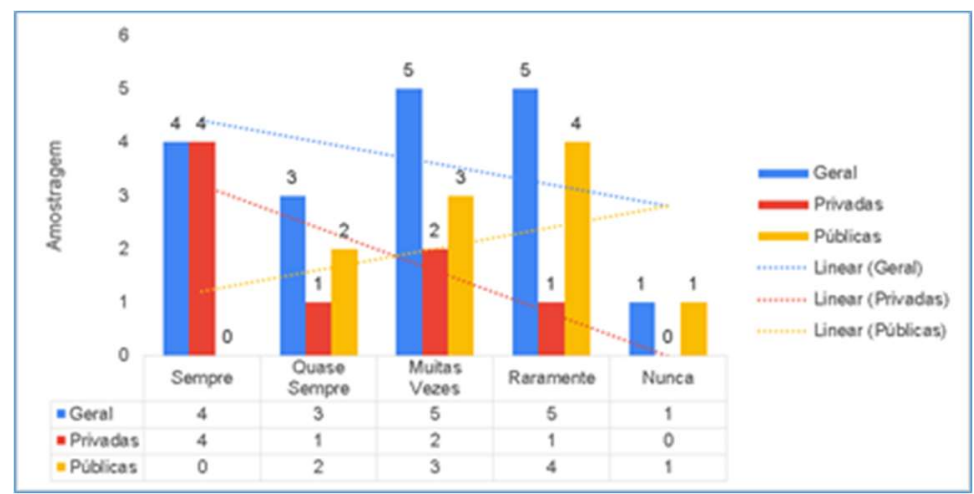

Gráfico 6: Frequência da remoção dos equipamentos computacionais que não estão em uso pelas IES.

Analisando por tipo de instituição, observa-se, no gráfico 6 , que $62,5 \%$ das instituições privadas tendem a remover equipamentos sem uso e $20 \%$ das públicas afirmaram que quase sempre retiram estes equipamentos, enquanto $50 \%$ raramente ou nunca fazem isto. O resultado obtido nas instituições públicas pode ser explicado pelas dificuldades que estas possuem devido aos normativos para desfazimento relacionados aos bens do patrimônio. Quando a ação executada é pela remoção, 44,4\% das instituições, em geral, descartam os equipamentos através de empresas especializadas, sendo que deste total $62,5 \%$ são privadas e $37,55 \%$ são públicas. Um dado que surpreendeu é que nenhuma instituição pesquisada, seja pública ou privada, realiza destinação para reciclagem.

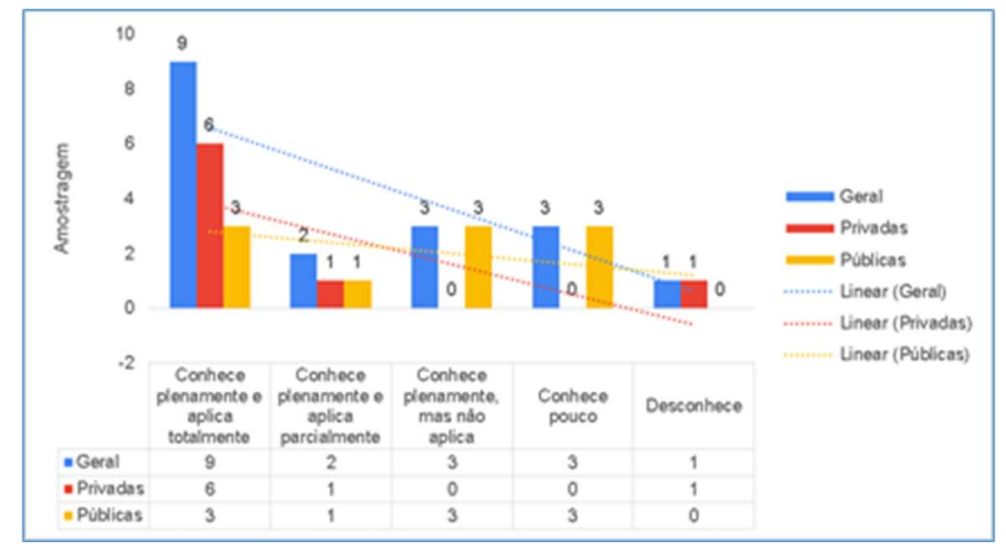

Gráfico 7: Nível de conhecimento da legislação sobre descarte de resíduos eletroeletrônicos.

O gráfico 7 descreve se as instituições têm conhecimento sobre a legislação de descarte de resíduos eletroeletrônicos, que no caso é a Política Nacional de Resíduos Sólidos (PNRS). Os resultados indicaram que $50 \%$ das instituições informam que conhecem a legislação plenamente e aplicam totalmente. Das instituições privadas, $75 \%$ afirmaram que conhecem e aplicam plenamente. Esse número está alinhado com o fato de 
que as instituições privadas destinam os resíduos de forma correta. No caso das públicas apenas 30\% delas afirmaram conhecer plenamente e aplicar totalmente.

O gráfico 8, por sua vez, refere-se à aferição do grau de atendimento à legislação por parte das instituições no momento do descarte dos produtos eletroeletrônicos. 50\% das IES relataram que sempre ou quase sempre conseguem cumprir o que está posto em legislação. Novamente, percebeu-se que o resultado foi alavancado devido às IES privadas, uma vez que, no caso das instituições públicas, $80 \%$ responderam que raramente adotam a prática. Quando considerada a empresa receptora do descarte, foi averiguado que apenas um terço das IES respondentes sempre verificam o cumprimento da lei por parte de seu fornecedor de serviço de descarte.

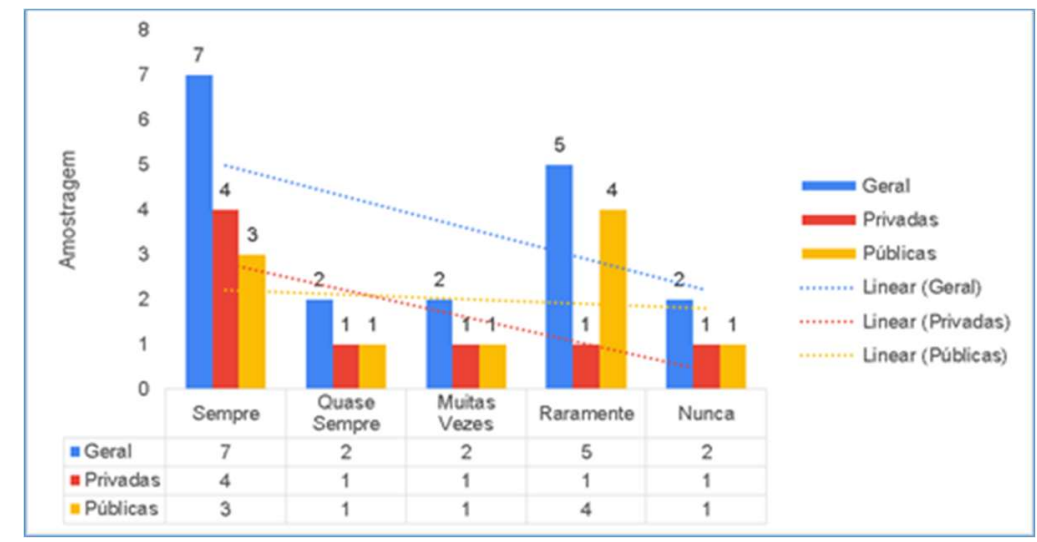

Gráfico 8: Grau de atendimento à legislação no descarte dos produtos eletroeletrônicos das IES.

Também procurou-se averiguar se as instituições conheciam a norma que trata da questão da responsabilidade social e se aplicavam seus conceitos. 55,5\% dos respondentes assinalaram conhecê-la plenamente, sendo que $33,3 \%$ a aplicam totalmente e $22,2 \%$ apenas parcialmente, conforme pode ser visto no gráfico 9. Dentre as IES que conhecem, metade são públicas e metade privadas. Esse equilíbrio se altera quando se observa que a maioria das IES públicas desconhece o regramento.

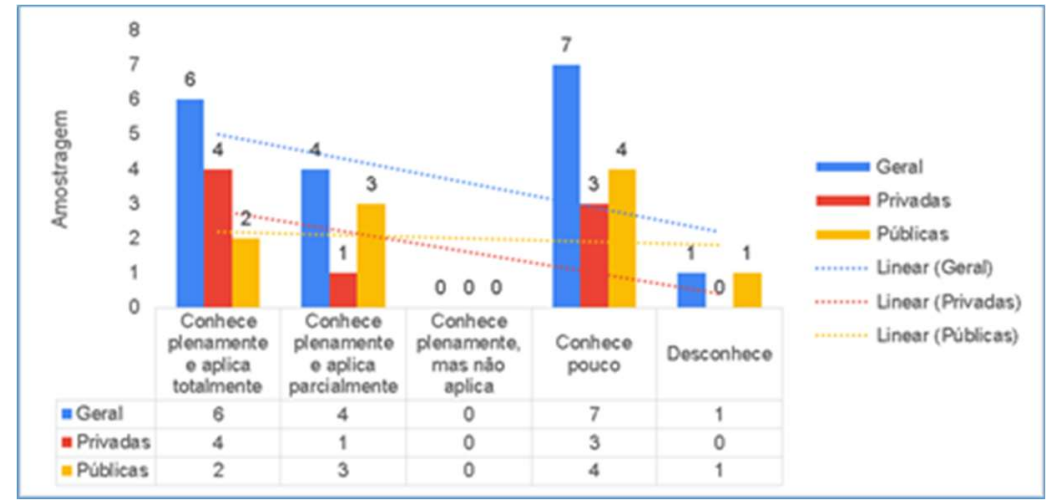

Gráfico 9: Nível de conhecimento e aplicação da norma de responsabilidade social.

Por fim, o gráfico 10 apresenta os resultados acerca da percepção dos respondentes sobre o quanto a tecnologia da informação verde pode realmente trazer benefícios para a instituição. Quase que $80 \%$ dos respondentes entendem que o conjunto destas práticas promove benefícios. De fato, identificar que algumas práticas adotadas pela instituição trazem resultados positivos, e que estão enquadradas em conceitos sustentáveis, pode ser um elemento motivador na implantação da TI Verde nas IES. 


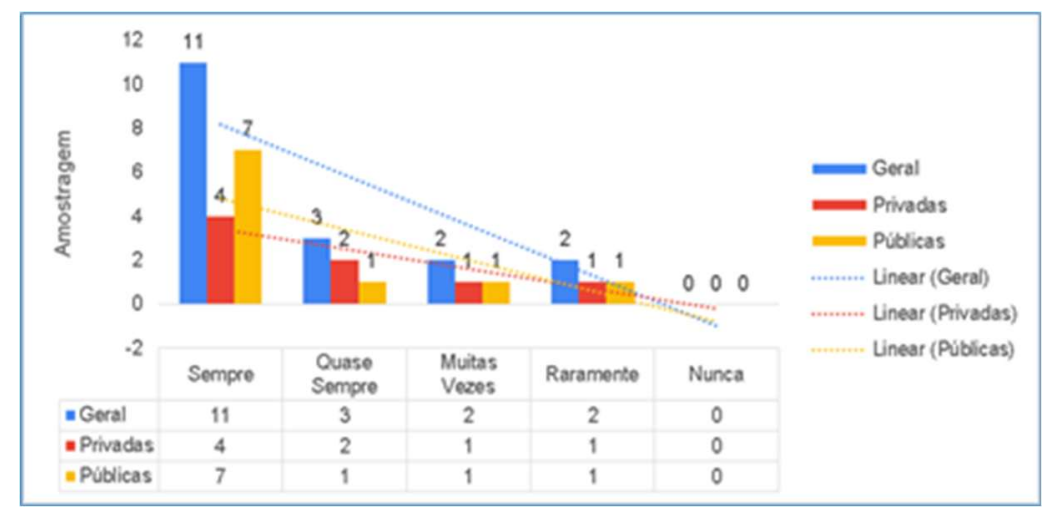

Gráfico 10: Percepção se a TI Verde promove benefícios para a instituição.

Ao analisar as dificuldades de implantação e compreender como as pressões institucionais e a legislação ambiental influenciam na implementação das práticas de TI Verde no âmbito das IES pesquisadas, foi possível inferir sobre a importância de disponibilizar recomendações plausíveis e acessíveis aos seus gestores, indicando qual o caminho mais adequado a seguir para adoção dessas práticas. Por este motivo, como produto da pesquisa, foi elaborada uma cartilha de recomendações efetivas sobre os possíveis problemas e soluções no contexto das IES.

\section{Proposta de uma cartilha de recomendações para adoção de práticas de TI Verde em IES}

Após todo o levantamento e análise descritiva dos dados, ficou constatado que nenhuma IES tinha implantado um Plano de Gestão de Resíduos Sólidos (PGRS), que é o documento técnico que comprova a capacidade de uma instituição gerir de modo ambientalmente correto todos os resíduos que gera, conforme exige a PNRS. Assim sendo, percebeu-se a necessidade e a importância de elaborar orientações para os gestores no sentido de preencher esta lacuna e descrever quais as maiores dificuldades percebidas e como estas poderiam ser solucionadas na prática para aprimorar a gestão ambiental. Então, foi elaborada uma cartilha de recomendações com 23 (vinte e três) problemas identificados com as respectivas sugestões para adoção de práticas de TI Verde por parte das IES.

Por questões de limitações de espaço, para o presente artigo, foram selecionadas seis páginas da cartilha para apresentação e descrição, abordando os seguintes problemas: desconhecimento sobre TI Verde; desconhecimento sobre programas de sustentabilidade; não compram produtos com selo de qualidade ambiental; não possuem o hábito de copiar práticas bem-sucedidas de instituições coirmãs ou concorrentes; desconhecimento sobre formas de reciclagem e descarte de equipamentos obsoletos.

Inicialmente, foi identificada a falta de conhecimento sobre o conceito de TI Verde e acerca dos programas de sustentabilidade. Ressalta-se a importância de se elaborar um procedimento para auxiliá-las a conhecer sobre a TI Verde e sobre os principais programas de gestão sustentável, a fim de que possam criar condições para disseminá-los entre os funcionários. Assim, na figura 1, estão listados os supracitados problemas e as sugestões propostas, envolvendo, por exemplo, a seleção de reportagens e artigos, a promoção de seminários e a contratação de consultoria especializada. 


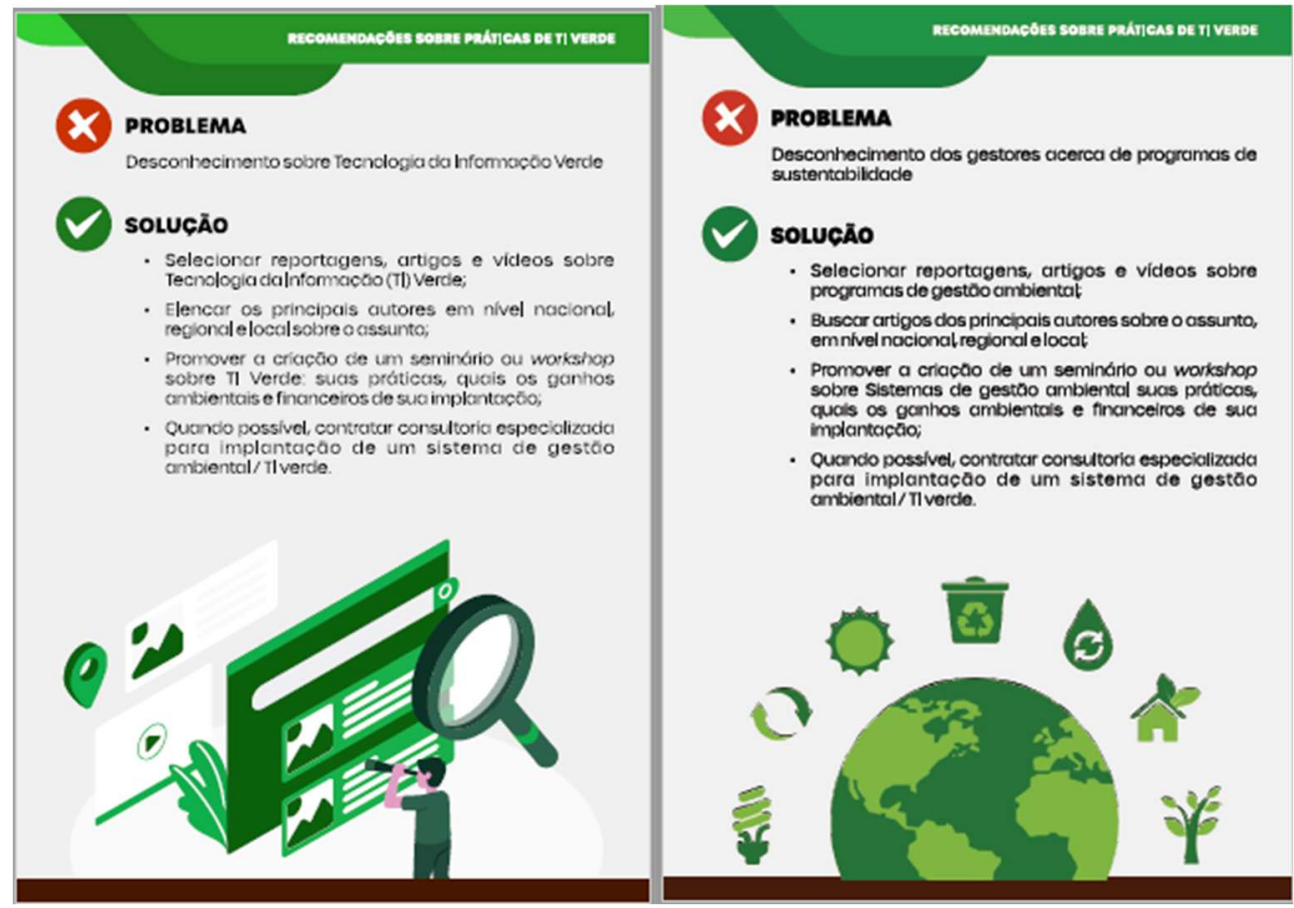

Figura 1: Problemas e soluções relacionados ao desconhecimento dos gestores das IES sobre TI Verde.

Outro ponto importante da cartilha (Figura 2) foram as ações de produção mais limpa, que é uma ferramenta pouco conhecida pelas instituições. Uma das linhas de atuação prevê substituição de peças e equipamentos com materiais perigosos por outros com o mesmo desempenho, mas que não agridam o meio ambiente. Nas instituições públicas, percebeu-se que, devido à escassez de recursos financeiros no setor público, situações que podem encarecer processos licitatórios são naturalmente descartadas. A recomendação indicada neste caso é introduzir no processo de compras da IES para aquisição de produtos com selo ambiental de qualidade ou que comprovadamente os equipamentos sejam isentos de materiais perigosos. Na impossibilidade desta compra, deve-se solicitar do fornecedor que se responsabilize pela logística reversa, algo que foi reforçado com a regulamentação do decreto federal 10.240/2020.

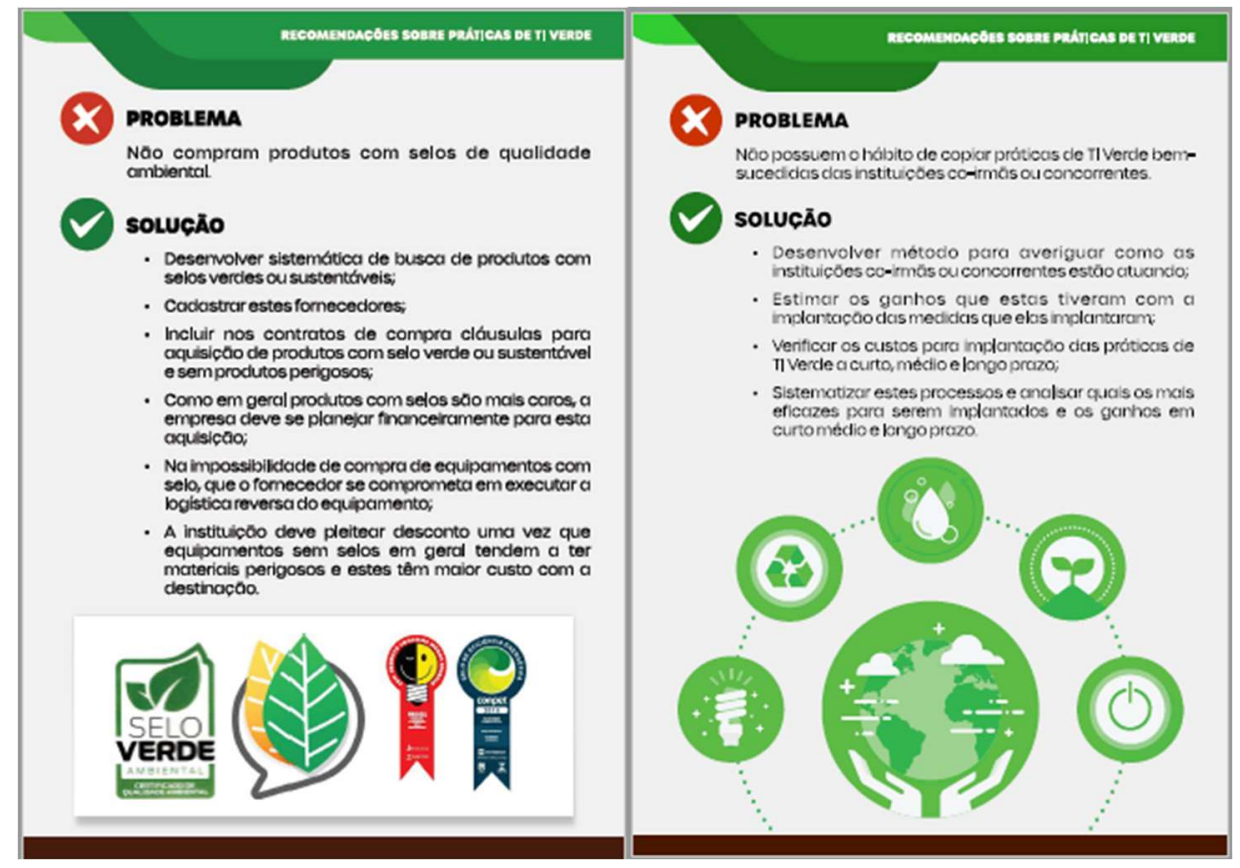

Figura 2: Problema e soluções relacionadas às compras de equipamentos e ao hábito de copiar práticas. 
Também foi possível identificar que as instituições privadas tendem a copiar as práticas bemsucedidas das coirmãs, já as públicas o fazem raramente. Práticas que dão certo deveriam ser observadas e aperfeiçoadas ou adaptadas à realidade de cada instituição. Uma recomendação importante presente na cartilha (Figura 2) é que as instituições devem desenvolver mecanismos de busca destas boas práticas em outras instituições sejam coirmãs ou concorrentes, inclusive como forma de reduzir custos.

Outro ponto importante presente na cartilha refere-se aos problemas vinculados ao descarte dos equipamentos eletroeletrônicos (Figura 3). A frequência de remoção é um indicativo importante e observouse uma divergência: IES privadas demonstram uma tendência em remover equipamentos eletrônicos em desuso com maior frequência do que as públicas. Provavelmente pela dificuldade das IES públicas em executar o descarte devido a normativos e legislações de proteção ao patrimônio público.

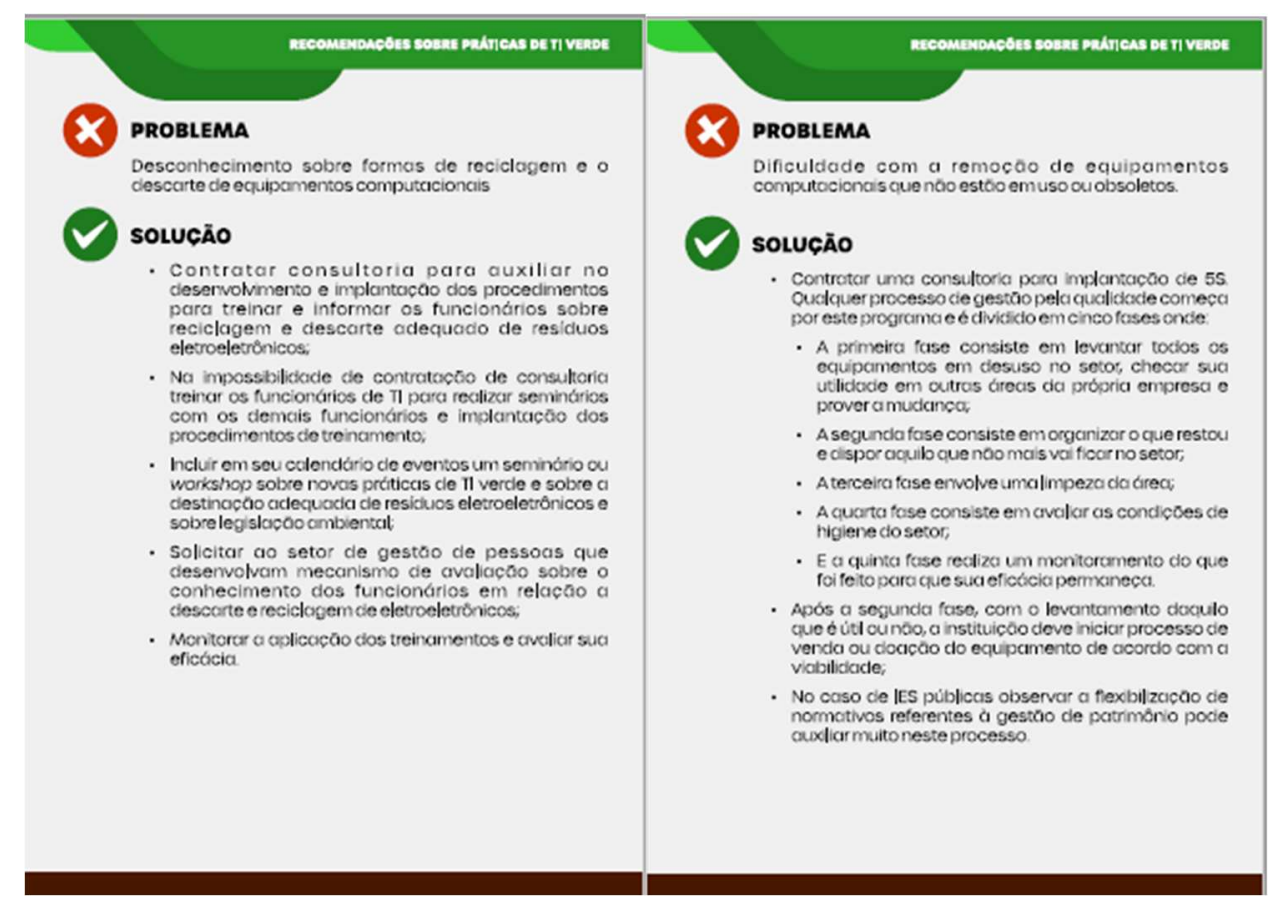

Figura 3: Problemas e soluções relacionados ao descarte e reciclagem de equipamentos das IES.

Ainda sobre as dificuldades de remoção de equipamentos, as IES devem desenvolver procedimentos para retirada de equipamentos que estão em desuso, isto é importante para que as instituições organizem o espaço de seus setores, melhorando o ambiente de trabalho. O destino do material descartado é uma questão que deve ser muito bem controlada pelas instituições, pois estes são os maiores causadores de impactos ambientais observados na indústria de eletroeletrônicos. Inclusive, existem implicações legais envolvidas no que tange a PNRS, que prevê multas e interdições para quem descartar resíduos de forma imprópria.

\section{CONCLUSÕES}

A presente pesquisa realizou um estudo comparativo entre seis instituições de ensino superior públicas e privadas, localizadas no estado de Alagoas, procurando analisar as dificuldades de implantação das práticas da TI Verde à luz da legislação ambiental e da teoria institucional. Desta forma, a pesquisa de 
campo identificou que as IES em geral pouco conhecem a TI Verde e também não aplicam vários de seus conceitos. Também foi revelado que as IES desconhecem a maioria dos programas de sustentabilidade e existe dificuldade em executá-los, seja por desconhecimento ou pela impressão de que estes programas sempre custam caro. Essa percepção de custo ficou muito evidente na hora da instituição efetuar compras de equipamentos. Entre outros pontos, as IES ainda não perceberam que, ao adquirir equipamentos com selos ambientais de qualidade, podem de uma única vez atender a vários conceitos de sustentabilidade, barateando o processo que se imagina caro.

A destinação adequada dos resíduos foi outro um ponto que recebeu especial atenção na pesquisa, pois, foi observado que existem dificuldades das IES na hora de realizar a correta destinação de seus resíduos eletroeletrônicos. É fundamental para as IES sistematizar um procedimento de descarte destes equipamentos, pois o descumprimento da legislação ambiental vigente pode acarretar em multas.

Diante do panorama mapeado, percebeu-se a necessidade de elaborar orientações claras aos gestores acerca dos pontos mais vulneráveis, no formato de uma cartilha de recomendações para IES, norteando a adoção de práticas de TI verde, contendo um passo a passo, onde para cada um dos vinte e três problemas identificados propõe-se uma série de soluções para implantação dos conceitos.

Sobre as limitações da pesquisa, em que pese uma pesquisa quantitativa, a investigação precisa ser ampliada para outras IES, provavelmente de outros estados, para fins de generalização. Para o âmbito de Alagoas os resultados podem ser generalizados, uma vez que a amostra, em termos de instituições de ensino, pode ser considerada representativa. Para trabalhos futuros, sugere-se a aplicação do referido instrumento de coleta entre instituições de estados vizinhos, com o intuito de traçar um panorama da região Nordeste. Uma outra sugestão de pesquisa seria a realização de um novo levantamento, em um período de tempo após a entrega da cartilha de recomendações, com as mesmas IES participantes da presente pesquisa, para aferir se houve melhoria nos resultados.

\section{REFERÊNCIAS}

BARDIN, L.. Análise de conteúdo. São Paulo: Edições 70, 2011.

BRASIL. Lei Federal n. 12.305, de 02 de agosto de 2010. Institui a Política Nacional de Resíduos Sólidos. Brasília: DOU, 2010.

BRASIL. Decreto n. 10.240, de 12 de fevereiro de 2020. Dispõe sobre a implementação de sistema de logística reversa de produtos eletroeletrônicos e seus componentes de uso doméstico. Brasília: DOU, 2020.

BOSE, R.; LUO, X.. Green IT adoption: a process management approach. International Journal of Accounting and Information Management, v.20, n.1, p.63-77, 2012. DOI: http://doi.org.10.1108/18347641211201081

CHEN, A. J.; WATSON, R. T.; BOUDREAU, M. C.; KARAHANNA, E.. An Institutional Perspective on the Adoption of Green IS \& IT. Australasian Journal of Information Systems, v.17, n.1, 2011. DOI: http://doi.org/10.3127/ajis.v17i1.572
DEMAJOROVIC, J. A.; FERNANDES, E. E.; SOUZA, M. T. S.. Reverse Logistics Of E-Waste in Developing Countries: Challenges and Prospects for the Brazilian Model. Ambiente \& Sociedade, v.19, n.2, p.117-136, 2016. DOI: http://doi.org/10.1590/1809-4422ASOC141545V1922016

DIMAGGIO, P. J.; POWELL, W.. Jaula de ferro revisitada: isomorfismo institucional e racionalidade coletiva nos campos organizacionais. In: CALDAS, M. P.; BERTERO, C. O.. Teoria das organizações. São Paulo: Atlas, 2007.

DINIZ, N. R. F.. Gestão Ambiental em instituições públicas de ensino superior: processos de destinação de resíduos eletrônicos de informática. Dissertação (Mestrado em Rede em Administração Pública) - Universidade Federal de Viçosa, Viçosa, 2016.

GIANELLI, A.. Práticas sustentáveis em TI Verde no Instituto Federal de São Paulo: limites e possibilidades. Dissertação (Mestrado Interdisciplinar em Educação, Ambiente e Sociedade) - Centro Universitário das Faculdades Associadas de Ensino, São Paulo, 2016. 
GIL, A. C.. Métodos e técnicas em pesquisa social. 6 ed. São Paulo: Atlas, 2008.

JENKIN, T.; WEBSTER, J.; MCSHANE, L.. An agenda for green Information technology and systems research. Information and Organization, v.21, n.1, p.17-40, 2010. DOI: http://doi.org/10.1016/j.infoandorg.2010.09.003

KIM, Y. S.; KO, M.. Identifying Green IT Leaders with Financial and Environmental Performance Indicators. In: AMERICAS CONFERENCE ON INFORMATION SYSTEMS. Anais. Lima: AMCIS, 2010.

LEEUW, E. D.; HOX, J. J.; DILLMAN, D. A.. International Handbook of Survey Methodology. Jena: The European Association of Methodology, 2008.

LUNARDI, G. L.; ALVES, A. P. F.; SALLES, A. C.. TI verde e seu impacto na sustentabilidade ambiental. In: ENCONTRO DA ANPAD, 38. Anais. Rio de Janeiro, 2012.

LUNARDI, G.; SIMÕES, R.; FRIO, R. S.. TI VERDE: Uma análise dos principais benefícios e práticas utilizadas pelas organizações. Revista Eletrônica de Administração, v.20, n.1, p.1-30, 2014. DOI: http://doi.org/10.1590/S1413$\underline{23112014000100001}$

MAITINO NETO, R.; FAXINA, J. M.. TI Verde e Sustentabilidade. Revista de Ciências Exatas e Tecnologia, v.7, n.7, p.159-174, 2012.

MELVILLE, N.. Information Systems innovation for environmental sustainability. MIS Quarterly, v.34, n.1, p.121, 2010 .

MINOTTO, J. B.; MAGALHÃES, R. F.; RODRIGUES, E. A.. Elaboração e Implantação do Plano de Gerenciamento de Resíduos Sólidos na Universidade Federal do Rio Grande do Sul. In: CONGRESSO BRASILEIRO DE GESTÃO AMBIENTAL, 6. Anais. Porto Alegre, 2015.
MURUGESAN, S.. Harnessing green IT: Principles and practices. IEEE IT Professional, v.10, n.1, p.24-33, 2008.

RODRIGUES A. C.; GUNTHER, W. M. R.; BOSCOV, M. E. G.. Estimativa da geração de resíduos de equipamentos elétricos e eletrônicos de origem domiciliar: proposição de método e aplicação ao município de São Paulo, São Paulo, Brasil. Engenharia Sanitária Ambiental, v.20, n.3, p.437-447, 2015. DOI: http://doi.org/10.1590/S141341522015020000133701

SALLES, A. C.; ALVES, A. P. F.; DOLCI, D. B.; LUNARDI, G. L.. Tecnologia da Informação Verde: Um Estudo sobre sua Adoção nas Organizações. Revista de Administração Contemporânea, v.20, n.1, p.41-63, 2016. DOI: http://doi.org/10.1590/1982-7849rac20161887

SACHUCK, M. I.; TAKAHASHI, L. Y.; AUGUSTO, C. A.. Impactos da inovação tecnológica na competitividade e nas relações de trabalho. Caderno de Administração, v.16, n.2, p.57-66, 2008.

SADALLA, B. A.. Destinação de resíduos eletroeletrônicos em instituições de ensino superior do Estado de São Paulo: práticas adotadas na USP, UNICAMP e UFSCar. Dissertação (Mestrado em Política Científica e Tecnológica) Universidade Estadual de Campinas, São Paulo, 2019.

SCOTT, W. R.. Institutions and organizations. 2 ed Thousand Oaks: Sage, 2001.

SELZNIK, P.. Institutionalism: old new. Administrative Science Quartely, v.41, p.270-271, 1996.

WATANABE, F. P.; CANDIANI, G.. Gestão de resíduos de equipamentos eletroeletrônicos em instituições de ensino superior. Revista Ibero Americana de Ciências Ambientais, v.10, n.5, p.169-186, 2019. DOI: http://doi.org/10.6008/CBPC2179-6858.2019.005.0016

A CBPC - Companhia Brasileira de Produção Científica (CNPJ: 11.221.422/0001-03) detém os direitos materiais desta publicação. Os direitos referem-se à publicação do trabalho em qualquer parte do mundo, incluindo os direitos às renovações, expansões e disseminações da contribuição, bem como outros direitos subsidiários. Todos os trabalhos publicados eletronicamente poderão posteriormente ser publicados em coletâneas impressas sob coordenação da Sustenere Publishing, da Companhia Brasileira de Produção Científica e seus parceiros autorizados. Os (as) autores (as) preservam os direitos autorais, mas não têm permissão para a publicação da contribuição em outro meio, impresso ou digital, em português ou em tradução. 